\title{
Traction-assisted endoscopic full-thickness resection followed by O-ring and over-the-scope clip closure in the stomach: an animal experimental study $\square$
}

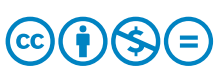

\author{
Authors \\ Nishiyama ${ }^{3}$, Hirohito Mori ${ }^{1}$, Tsutomu Masaki ${ }^{1}$ \\ Institutions \\ 1 Department of Gastroenterology and Neurology, \\ Kagawa University, Kagawa, Japan \\ 2 Department of Gastroenterological Surgery, Kagawa \\ University, Kagawa, Japan \\ 3 Department of Pharmacology, Kagawa University, \\ Kagawa, Japan
}

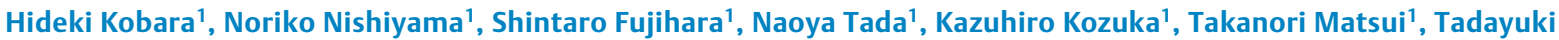
Takata', Taiga Chiyo', Nobuya Kobayashi ${ }^{1}$, Koji Fujita ${ }^{1}$, Tatsuo Yachida ${ }^{1}$, Keiichi Okano ${ }^{2}$, Yasuyuki Suzuki ${ }^{2}$, Akira

submitted 31.7 .2020

accepted after revision $\quad 2.10 .2020$

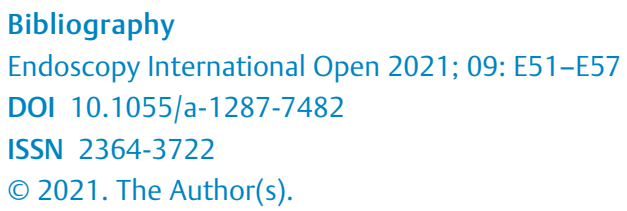

This is an open access article published by Thieme under the terms of the Creative Commons Attribution-NonDerivative-NonCommercial License, permitting copying and reproduction so long as the original work is given appropriate credit. Contents may not be used for commecial purposes, or adapted, remixed, transformed or built upon. (https://creativecommons.org/licenses/by-nc-nd/4.0/)

Corresponding author

Hideki Kobara, MD, PhD, Department of Gastroenterology and Neurology, Faculty of Medicine, Kagawa University, 1750-1 Ikenobe, Miki, Kita, Kagawa 761-0793, Japan

Fax: +81-87-891-2158

kobara@med.kagawa-u.ac.jp

\section{ABSTRACT}

Background and study aims Exposed endoscopic fullthickness resection (EFTR) enables the operator to obtain a sufficient surgical margin. However, insufflation leakage and secure endoscopic full-thickness closure (EFTC) remain problematic. This study aimed to evaluate the safety and feasibility of a new exposed EFTR.

Patients and methods Exposed EFTR was performed for $2-\mathrm{cm}$ virtual lesions in different locations of the upper stomach in four dogs. EFTR mainly involved half-circumferential EFTR of the endpoint and clip-line traction. Pulley traction was applied with the forward approach for the greater curvature. EFTC involved endoscopic ligation with O-ring closure to diminish insufflation leakage, followed by over-the-scope clip closure.

Results Complete resection and technical success were achieved in all four cases. One case of intraoperative bleeding was endoscopically managed. No postoperative complications occurred in any cases. The median maximum resected size was $27.5 \mathrm{~mm}$. The median procedure time of the total operation, EFTR, and EFTC was 76, 37, and 35.5 minutes, respectively. The 1 -month survival rate was $100 \%$. Conclusions This therapeutic strategy may lead to the establishment of exposed EFTR.

\section{Introduction}

Endoscopic full-thickness resection (EFTR) is indicated for upper gastrointestinal subepithelial tumors originating in the muscularis propria (MP), especially $<3-\mathrm{cm}$ gastrointestinal stromal tumors (GISTs) suitable for removal via the mouth [1]. A recent study showed excellent outcomes of laparoscopic endoscopic cooperative surgery, which involves endoscopic navigation and tumor resection followed by laparoscopic suture closure [2]. Several unique techniques derived from endoscopic submucosal dissection have been further developed as mini- mally invasive endoluminal surgeries (i.e., "no-scar surgeries" without laparoscopic assistance). These techniques involve submucosal tunneling with endoscopic resection (STER) [3], exposed EFTR followed by endoscopic closure [4], and advanced non-exposed EFTR [5-8]. However, when a GIST is buried deep in the MP or exhibits extraluminal growth, STER in narrow working spaces might not easily achieve complete resection of GISTs with an intact capsule. Thus, exposed EFTR can more reasonably achieve a negative surgical margin. Because a larger perforation occurs in exposed EFTR, insufflation leakage increases the difficulty of maintaining a sufficient operative field, mana- 
ging intraoperative bleeds, and achieving secure endoscopic full-thickness closure (EFTC) of the defect, which migrates toward the peritoneal cavity. This study aimed to evaluate the safety and feasibility of a new exposed EFTR.

\section{Patients and methods}

Four 11-to 13-month-old female beagles were enrolled in this study from December 2019 to March 2020. Exposed EFTR was performed for virtual GISTs of approximately $2-\mathrm{cm}$ diameter at four locations in the upper stomach where GISTs often occur [2]: the greater and lesser curvatures and anterior and posterior walls. The dogs were fasted for 24 hours before the intervention. Procedures were performed under general anesthesia with intubation. The dogs received an antibiotic and proton pump inhibitor once daily for 2 days postoperatively. After the absence of significant symptoms, such as loss of appetite, tarry stool, and ptyalism were confirmed in all dogs during the 2 days of fasting, a solid diet was started on postoperative day 3. This study was approved by the institutional review board based on the Regulations and Guidelines of Animal Experiments of Kagawa University (Registration No. A248, Approval No. 20619).

\section{Experimental equipment}

The following equipment was used: gastroscope (Q260); Olympus, Tokyo, Japan), over-the-scope clip (OTSC) system and Twin Grasper (TG) forceps (Ovesco Endoscopy GmbH, Tübingen, Germany), hemoclips (HX-610-090L; Olympus), endoscopic variceal ligation device (MD-48720U; Sumius, Tokyo, Japan), loop cutter (FS-5L-1; Olympus), endoscopic knives [DualKnife (KD-650 L); Olympus and ITknife2 (KD-611 L); Olympus], hemostatic forceps (FD-410 LR; Olympus), glycerol for injection (Chugai Pharmaceutical Co., Ltd., Tokyo, Japan), carbon dioxide insufflation device (UCR; Olympus), and electrosurgical unit (VIO 300 D; Erbe Elektromedizin, Tübingen, Germany). The settings for EFTR were as follows: cut mode, Endocut I, effect 2, duration 3, interval 2 for mucosal incision; coagulation mode, Swift Coag, effect 3, $80 \mathrm{~W}$ for submucosal trimming and fullthickness resection; and Soft Coag, effect 6, $80 \mathrm{~W}$ for hemostasis.

\section{Procedure ( Video 1 )}

Traction-assisted EFTR

Step 1: Groove After marking around the lesion, whole-circumferential mucosal incision and submucosal trimming were performed until the muscle layer appeared( $\triangleright$ Fig. $1 \mathbf{a})$.

Step 2: Ring-anchor for subsequent EFTC At both edges around the prepared two-point marking, an approximately 5$\mathrm{mm}$ perforated slit hole was created using the Dual Knife on the exposed MP. A hemoclip that captured a handmade ringthread (4-cm diameter with 3-0 surgical nylon) was firmly anchored on the edge of the slit hole to grasp the full-thickness layer. The same procedure was then performed on the opposite side( $\triangleright$ Fig. 1b). This was performed to prepare for possible insufflation leakage during subsequent EFTC.

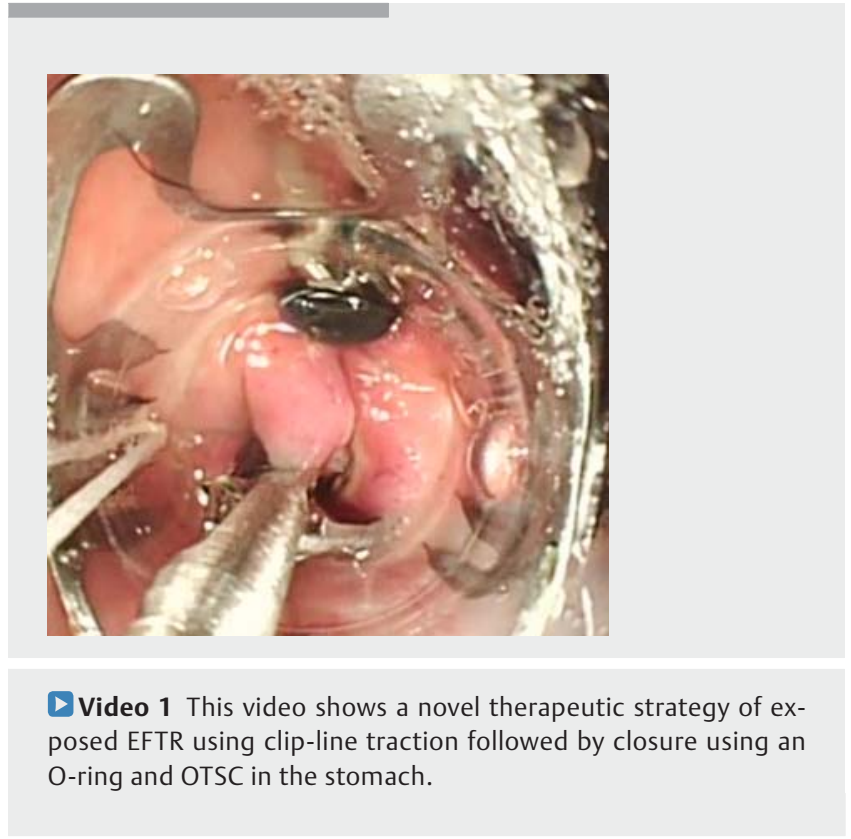

Step 3: Half-circumferential EFTR of endpoint Half-circumferential EFTR was performed from the slit holes on both sides toward the distal side( $\vee$ Fig.1c). Careful attention was paid to avoid cutting the ring-thread.

Step 4: Traction using clip-line method Traction was applied to the lesion using a previously described clip-with-line method [9]. Pulley traction was used in the forward approach [10] ( Fig. 1d), while the simple clip-line method was used in the retroflexed approach ( $\triangleright$ Fig. 1 e).

Step 5: Complete EFTR EFTR was achieved by resecting the residual full-thickness layer under traction ( $\mathbf{F i g . 1 f}$ ).

\section{EFTC using O-ring and OTSC}

Step 1: Endoscopic ligation with O-ring closure (E-LOC) As previously described [11], E-LOC was introduced to approximate large defects ( $>$ Fig. 2a). A hemostatic forceps was used to capture the prepared ring-thread and pull it into the cap of the endoscopic variceal ligation device ( $\triangleright$ Fig.2b). After the two deployed hemoclips were pulled into the cap, an O-ring was fired around these hemoclips ( $\triangleright$ Fig. 2 c). When the tails of these hemoclips were caught in the omentum, they were released using grasping forceps so that the hemoclips could move freely. The ring-thread was cut with a loop cutter.

Step 2: TG-assisted OTSC closure The approximated fullthickness defect was grasped with the TG ( $\nabla$ Fig. $2 \mathbf{d}$ ) and closed with two OTSCs (type gc, $10 \mathrm{~mm}$ ) ( Fig. 2e). The OTSCs were deployed directly around the fired O-ring to compensate for the space between the hemoclips and OTSCs.

Step 3: Mucosal closure The exposed mucosa was closed using hemoclips, resulting in complete EFTC ( $\triangleright$ Fig. 2f).

During the entire procedure, bleeding was managed by using hemostatic forceps. A $20 \mathrm{G}$ needle (Nipro Corporation, Osaka, Japan) was percutaneously inserted to evacuate excessive intra-abdominal air. Representative endoscopic images obtained during EFTR and EFTC are shown in > Fig.3a, > Fig. 3b, $>$ Fig. 3c, $>$ Fig. 3d, > Fig.3e, and > Fig. 3f. 


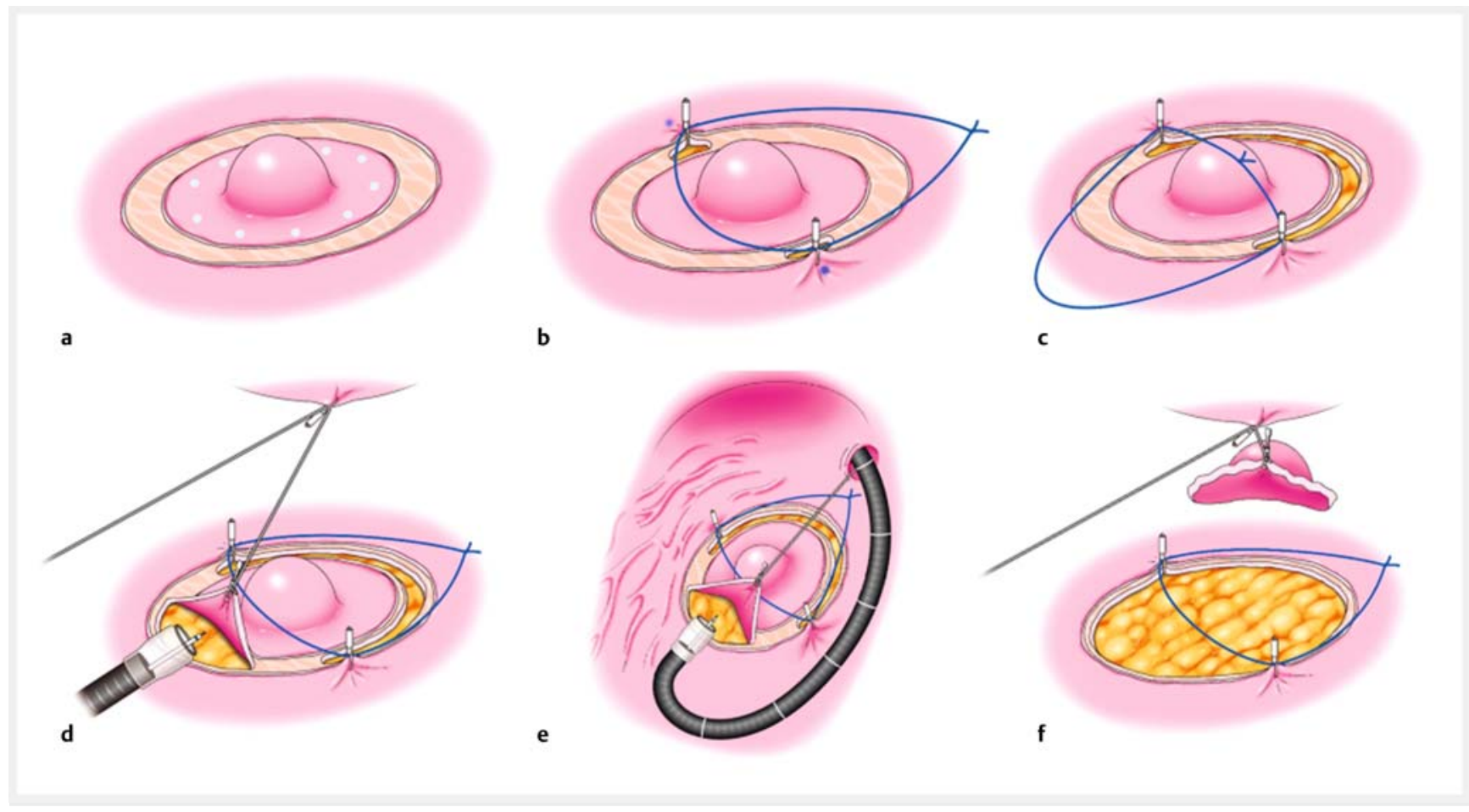

- Fig. 1 Schema for traction-assisted endoscopic full-thickness resection (EFTR). a Whole circumferential mucosal and submucosal incision (groove). b Ring-anchor for subsequent closure. c Half circumferential EFTR of endpoint. d Pulley traction using clip-line in forward approach. e Simple clip-line traction in retroflexed approach. f Complete EFTR
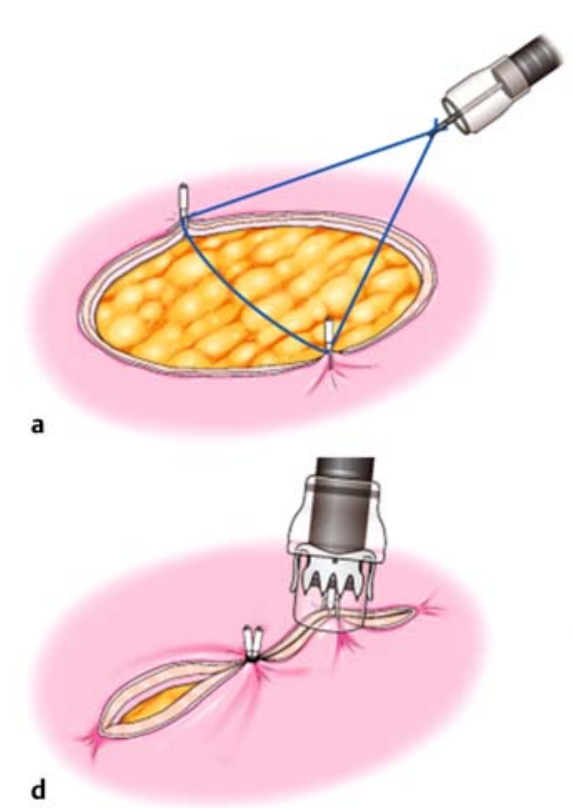

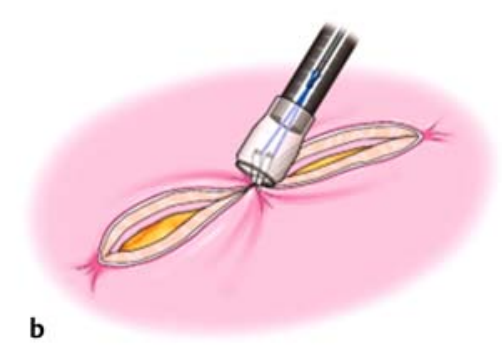

b

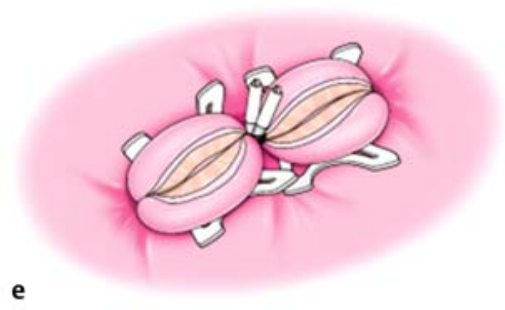

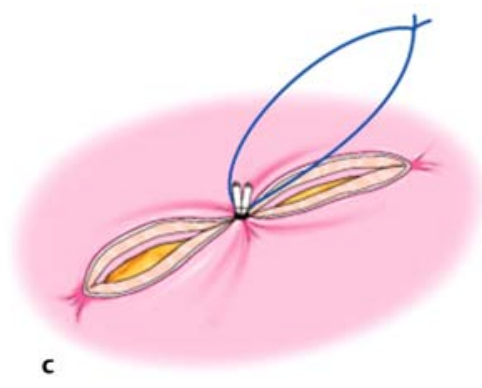

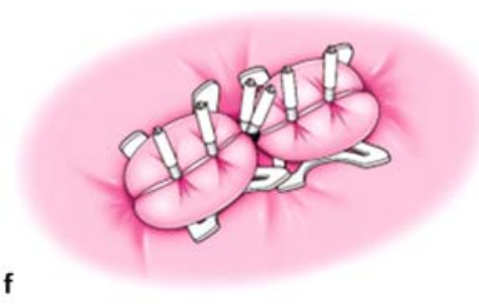

- Fig. 2 Schema for endoscopic full-thickness closure (EFTC) using O-ring and OTSC. a Capture of the prepared ring-thread. b Two deployed hemoclips captured in endoscopic variceal ligation cap by pulling the thread. c Firing of an O-ring. E-LOC diminishes insufflation leakage and approximates the large defect. d Twin grasper (TG)-assisted OTSC closure. Easy TG maneuver to grasp full-thickness layer. e Deployment of two OTSCs. f Mucosal closure using hemoclips. Endoscopic ligation with O-ring closure, E-LOC. 

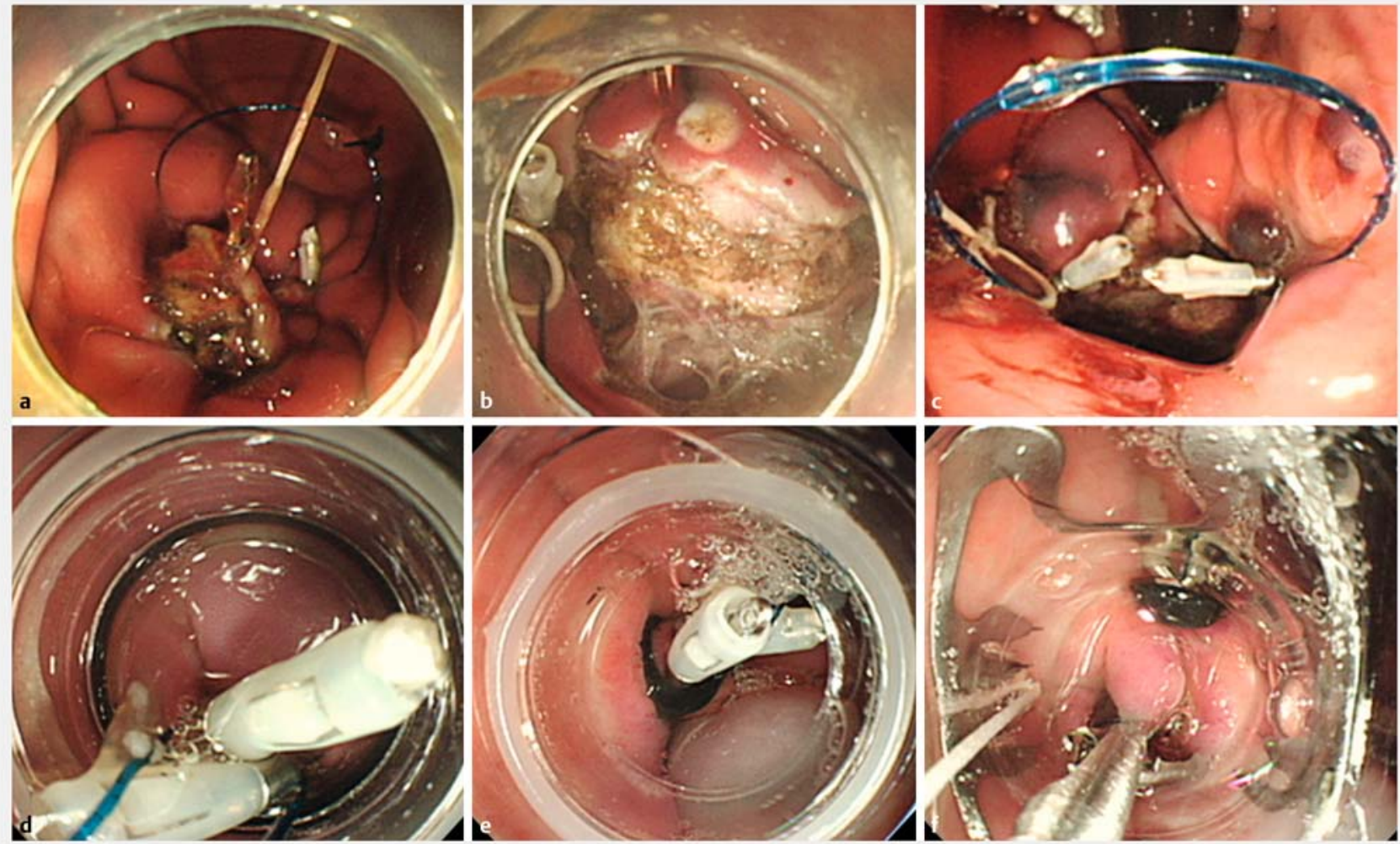

- Fig. 3 Representative images of EFTR and EFTC. a Forward approach: pulley traction using clip-line at greater curvature. b Retroflexed approach: simple clip-line traction at lesser curvature. $\mathbf{c}$ Ring-anchor prepared for EFTC in the section of EFTR. $\mathbf{d}$ Two deployed hemoclips captured in the ligation cap by pulling the thread. e Firing of an O-ring. f TG-assisted OTSC closure.

\section{Outcome measures}

The primary outcome measure was the complete resection rate. Complete resection was defined as a negative lateral margin and macroscopic or histological confirmation of a full-thickness wall. The secondary outcome measures were technical success, intraoperative or postoperative complications, maximum resection size, and 1-month survival. An intraoperative complication was defined as spurting bleeding or other organ injury. The procedure times of the total operation, EFTR, and EFTC were measured. The total procedure time was defined as the time from marking the dots to complete closure.

\section{Results}

Complete resection and technical success were achieved in all four locations ( Fig. 4a, > Fig. 4b, \ Fig.4c, \ Fig. 4d). Intraoperative bleeding occurred in one case during full-thickness precutting. No postoperative complications occurred. The median maximum resection size (synonymous with the perforated defect size) was 27.5 (range, 25-30) mm. The 1-month survival rate was $100 \%$. The median procedure time of the total operation, EFTR, and EFTC was 76 (49-92), 37 (24-51), and 35.5 (25-48) minutes, respectively. These outcomes are summarized in $>$ Table 1. Endoscopic examination on postoperative day 30 showed no anastomotic leakage. The macroscopic and
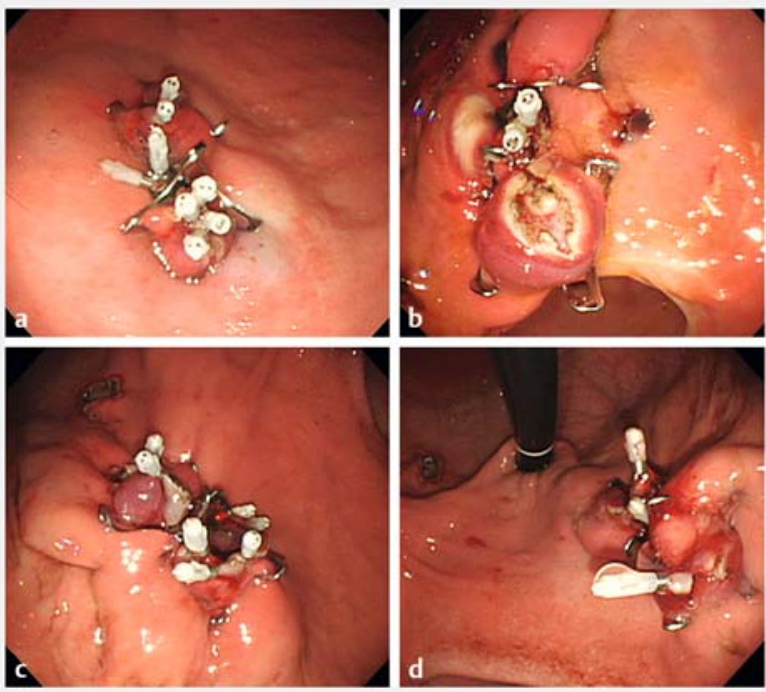

Fig. 4 Anastomotic site of exposed EFTR at four locations in the upper stomach. a Greater curvature. b Lesser curvature. c Anterior wall. d Posterior wall. 
- Table 1 Outcomes of exposed EFTR and EFTC.

\begin{tabular}{|c|c|c|c|c|c|c|c|c|c|c|}
\hline \multirow{2}{*}{$\begin{array}{l}\text { Case } \\
\text { no. }\end{array}$} & \multirow{2}{*}{$\begin{array}{l}\text { Location } \\
\text { of upper } \\
\text { stomach }\end{array}$} & \multirow{2}{*}{$\begin{array}{l}\text { Com- } \\
\text { plete } \\
\text { resec- } \\
\text { tion }\end{array}$} & \multirow{2}{*}{$\begin{array}{l}\text { Techni- } \\
\text { cal } \\
\text { suc- } \\
\text { cess }\end{array}$} & \multirow{2}{*}{$\begin{array}{l}\text { Intraoper- } \\
\text { ative com- } \\
\text { plications }\end{array}$} & \multirow{2}{*}{$\begin{array}{l}\text { Post- } \\
\text { operative } \\
\text { complica- } \\
\text { tions }\end{array}$} & \multicolumn{3}{|c|}{ Procedure time, min } & \multirow{2}{*}{$\begin{array}{l}\text { Resected } \\
\text { maxi- } \\
\text { mum } \\
\text { size }\end{array}$} & \multirow{2}{*}{$\begin{array}{l}\text { 1-month } \\
\text { survival }\end{array}$} \\
\hline & & & & & & Total & Resection & Closure & & \\
\hline 1 & $\begin{array}{l}\text { Greater } \\
\text { curvature }\end{array}$ & Yes & Yes & None & None & 75 & 45 & 30 & 30 & Yes \\
\hline 2 & $\begin{array}{l}\text { Lesser } \\
\text { curvature }\end{array}$ & Yes & Yes & Bleeding ${ }^{1}$ & None & 77 & 29 & 48 & 25 & Yes \\
\hline 3 & $\begin{array}{l}\text { Anterior } \\
\text { wall }\end{array}$ & Yes & Yes & None & None & 49 & 24 & 25 & 30 & Yes \\
\hline 4 & $\begin{array}{l}\text { Posterior } \\
\text { wall }\end{array}$ & Yes & Yes & None & None & 92 & 51 & 41 & 25 & Yes \\
\hline
\end{tabular}

histological findings of the resected specimens and anastomoses are shown in > Fig. 5a, > Fig. 5b, > Fig.5c, > Fig. 5d, > Fig. 5e, and $>$ Fig. $5 f$.

\section{Discussion}

This is the first animal experimental study to demonstrate the procedural strategy of exposed EFTR using clip-line traction and novel EFTC technique using an O-ring and OTSC in the stomach. Exposed EFTR has several advantages, including achieving simple whole-circumferential resection and intact tumor resection.

Our exposed EFTR technique involves whole-circumferential submucosal dissection and full-thickness muscle-serosa resection. The two-step procedure can coagulate exposed vessels identified in gaps between muscle layers. Importantly, technical tricks are required to manage thick vessels on the serosal side and resect the lesser or greater curvature adhered to the serosa. We performed traction using the clip-line method [9, $10]$ to successfully manage these situations. EFTR was completed without severe complications in all four locations of the upper stomach within an acceptable procedure time (median of 76 min for total operation and 37 min for EFTR). In this small case series, we found no difference in technical difficulty among the four upper stomach locations. However, the procedure time may have been influenced by the severity of adhesion between the omentum and serosa because dissection of the severely adhered lesser omentum took the longest time in the posterior wall. A large-scale study showed the superiority of traction-assisted EFTR $(n=64)$ over non-assisted EFTR $(n=128)$ in terms of the total procedure time (44.2 vs. $54.2 \mathrm{~min}$ ) and complication rate (3.1\% vs. $12.5 \%$ ) [12]. However, the description of the circumferential resection order was unclear. In our previous experience, the endpoint of the distal side was invisible, resulting in excessive resection and tumor damage. Thus, half-circumferential EFTR of the endpoint on the distal side should be attempted before use of traction. Moreover, use of traction has been reported with the retroflexed approach alone. The forward approach is needed for the greater curvature.

EFTC is challenging for large perforated defects. The keys to success include maintenance of a sufficient working space and achievement of inverted "serosa-serosa apposition." The OTSC, a full-thickness clipping device, enables serosa-serosa apposition [13]. However, even with TG assistance, OTSC closure sometimes fails because of a difficult TG maneuver and insufflation leakage. Thus, our E-LOC technique was used during EFTR [11]. E-LOC reduced insufflation leakage and enabled separation of a large defect into two small slits resembling sunglasses. The TG was then easily maneuvered to grasp the fullthickness layer, succeeding in serosa-serosa apposition. Traction and E-LOC also are mandatory to maintain an adequate operation field, which is influenced by insufflation leakage. A case series using OTSC before resection showed a high technical success rate in 16 cases [14]; however, full-thickness resection accounted for only $69 \%$ of cases. One clinical report revealed excellent outcomes of EFTR followed by OTSC closure [4]. Perforated defects of $<2 \mathrm{~cm}$ were successfully closed with single OTSC in all 23 cases. Thus, our method has potential to achieve OTSC closure for larger lesions because the median maximum defect size was $27.5 \mathrm{~mm}$. This finding also shows that the procedure may be indicated for the lesion with maximum size of $25 \mathrm{~mm}$. Meanwhile, centered hemoclips with O-ring may have a possibility of clip falling. These hemoclips dropped off in one of all cases on postoperative Day 30, while OTSCs remained in all cases. A previous study reported that inverted serosal apposition provided a more durable and reliable repair than everted mucosal apposition [15]. Thus, our procedure, which aimed to grasp a full-thickness layer using the TG and achieve its inverted closure, called for serosa-serosa apposition. Inverted full-thickness closure probably compresses the gap between the hemoclips and OTSCs, even if the hemoclips drop off at an early stage. The OTSCs were also deployed directly around the fired 

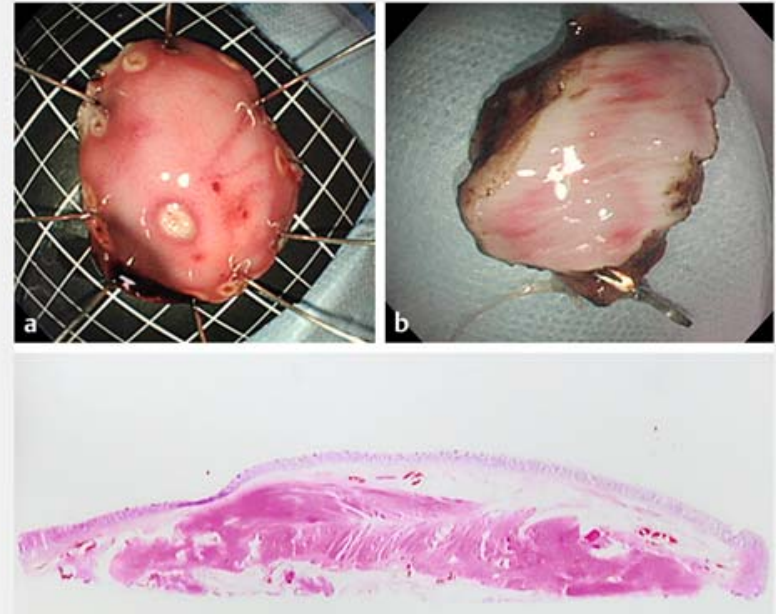

c
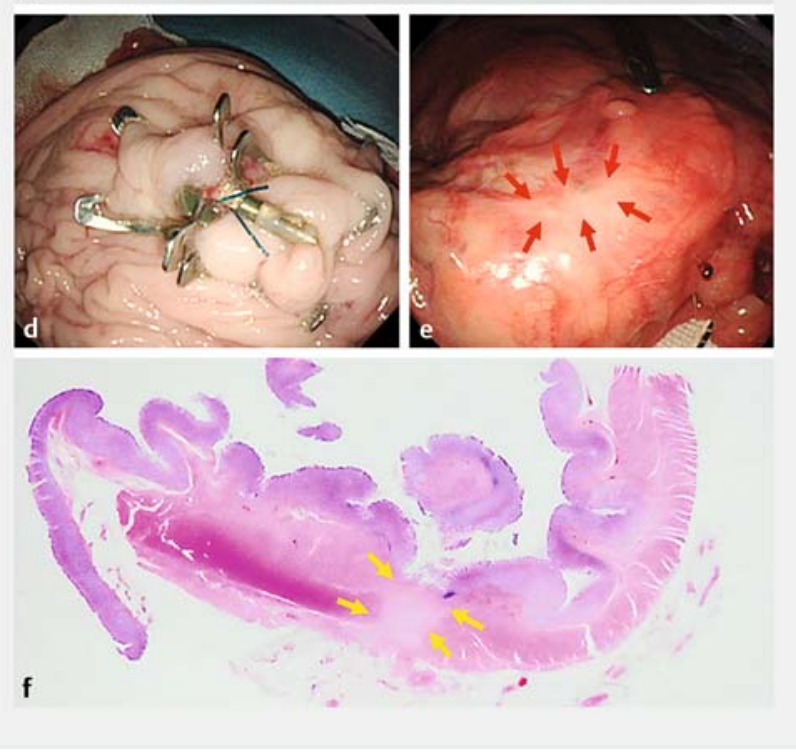

- Fig. 5 Macroscopic and histological findings from resected specimen and anastomosis on postoperative Day 30. a Mucosal side of resected specimen $(30 \times 25 \mathrm{~mm})$ obtained by complete resection. $\mathbf{b}$ Serosal side of full-thickness specimen. $\mathbf{c}$ Histological examination of full-thickness specimen with muscle and serosa (hematoxylin and eosin staining). d Anastomotic mucosal surface showing sustained OTSC closure. e Anastomotic serosal surface showing whitish healing scar (red arrows) without fistula. f Histological examination of the anastomotic site compensated by massive fibrotic tissues between resected layers (yellow arrows).

O-ring to compensate for the gap. A large-scale study should be conducted to evaluate the durability of this EFTC method.

Non-exposed EFTR is an advanced procedure in which closure is performed before resection without communication between the intra-lumens and extra-lumens. This may diminish the risk of postoperative peritonitis and broaden the indications to include early-stage gastric cancers with no lymph node metastasis and with severe submucosal fibrosis. Novel procedures using full-thickness suturing devices are still experimental in ex vivo $[5,6]$, in vivo $[7,8]$, and clinical settings [16].
This study had several limitations. First, the number of animals was small to minimize animal suffering. Second, the indication of the procedure was limited to $<2-\mathrm{cm}$ lesions in the upper stomach. This procedure may be contraindicated for lesions located in cardia or pyloric ring with a narrow lumen because of the potential risk of endoluminal stenosis from OTSC deployment. Third, the clinical indication is limited to GIST without ulcers because exposed EFTR is associated with a risk of peritoneal tumor seeding. Fourth, a leak pressure test was omitted because no leaks were confirmed in previous ex vivo experiments. Fifth, the use of two OTSCs and the TG forceps is expensive, thus, this method should be further simplified to reduce the cost when considering the clinical application. Further investigations are needed.

\section{Conclusions}

This experimental study demonstrated that clip-line traction, ELOC, and OTSC can be used to achieve exposed EFTR.

\section{Acknowledgements}

The authors thank Angela Morben, DVM, ELS, from Edanz group for editing a draft of this manuscript.

\section{Competing interests}

The authors declare that they have no conflict of interest.

\section{References}

[1] Zhou PH, Yao LQ, Qin XY et al. Endoscopic full-thickness resection without laparoscopic assistance for gastric submucosal tumors originated from the muscularis propria. Surg Endosc 2011; 25: 2926-2931

[2] Matsuda T, Nunobe S, Kosuga T et al. Society for the Study of Laparoscopy and Endoscopy Cooperative Surgery. Laparoscopic and luminal endoscopic cooperative surgery can be a standard treatment for submucosal tumors of the stomach: a retrospective multicenter study. Endoscopy 2017; 49: 476-483

[3] Xu MD, Cai MY, Zhou PH et al. Submucosal tunneling endoscopic resection: a new technique for treating upper Gl submucosal tumors originating from the muscularis propria layer (with videos). Gastrointest Endosc 2012; 75: 195-199

[4] Guo J, Liu Z, Sun S et al. Endoscopic full-thickness resection with defect closure using an over-the-scope clip for gastric subepithelial tumors originating from the muscularis propria. Surg Endosc 2015; 29 : 3356-3362

[5] Dobashi A, Rajan E, Knipschield MA et al. Endoscopic full-thickness resection using suture loop needle T-tag tissue anchors in the porcine stomach (with video). Gastrointest Endosc 2018; 87: 590-596

[6] Goto O, Sasaki M, Akimoto T et al. Feasibility and safety of third-space endoscopic full-thickness resection in ex vivo and in vivo porcine models. Endosc Int Open 2019; 7: E471-E476

[7] Mori H, Kobara H, Kazi R et al. Balloon-armed mechanical counter traction and double-armed bar suturing systems for pure endoscopic full-thickness resection. Gastroenterology 2014; 147: 278-280 
[8] Huberty V, Leclercq L, Hiernaux M et al. Endoscopic full-thickness resection using an endoluminal-suturing device: a proof-of-concept study. Endosc Int Open 2019; 7: E1310-E1315

[9] Jeon W], You IY, Chae HB et al. A new technique for gastric endoscopic submucosal dissection: peroral traction-assisted endoscopic submucosal dissection. Gastrointest Endosc 2009; 69: 29-33

[10] Li CH, Chen PJ, Chu HC et al. Endoscopic submucosal dissection with the pulley method for early-stage gastric cancer (with video). Gastrointest Endosc 2011; 73: 163-167

[11] Nishiyama N, Kobara $\mathrm{H}$, Kobayashi $\mathrm{N}$ et al. Novel endoscopic ligation with O-ring closure involving muscle layer of a gastric artificial defect. Endoscopy 2020: doi:10.1055/a-1149-8597

[12] Li B, Shi Q, Qi ZP et al. The efficacy of dental floss and a hemoclip as a traction method for the endoscopic full-thickness resection of sub- mucosal tumors in the gastric fundus. Surg Endosc 2019; 33: 38643873

[13] Kobara H, Mori H, Nishiyama $\mathrm{N}$ et al. Over-the-scope clip system: A review of 1517 cases over 9 years. J Gastroenterol Hepatol 2019; 34: 22-30

[14] Fähndrich M, Sandmann M. Endoscopic full-thickness resection for gastrointestinal lesions using the over-the-scope clip system: a case series. Endoscopy 2015; 47: 76-79

[15] Kobayashi M, Sumiyama K, Ban Y et al. Closure of iatrogenic large mucosal and full-thickness defects of the stomach with endoscopic interrupted sutures in in vivo porcine models: are they durable enough? BMC Gastroenterol 2015; 15: 5

[16] Schmidt A, Beyna T, Schumacher B et al. Colonoscopic full-thickness resection using an over-the-scope device: a prospective multicenter study in various indications. Gut 2018; 67: 1280-1289 